\title{
New Dietary Guidelines, New Opportunities
}

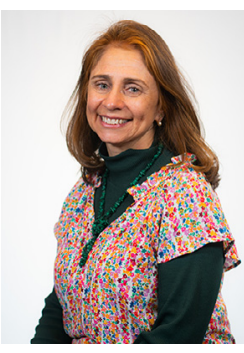

\section{UPSTREAM NUTRITION EDUCATION}

In my 35 years as a nutrition educator, I am often too busy doing the proverbial, "pulling drowning people out of the river to go upstream and stop people from getting in."

Yet, I had an opportunity to do upstream nutrition education with a fifth-grade class. It started during a pre-intervention survey about vegetables. A student asked, "can I write you a message?"

The message was "Kids my age DO NOT [sic] eat vegetables." In another lesson aimed at teaching why to drinking less soda and other sweetened beverages a student blurted out, "soda and fruit drinks are what we have, and that is what we drink." I stopped the planned activities and asked the students to share. They told me how soda, fruit drinks, chips, and candy were everywhere in their world while vegetables were mostly absent. I listened and thought about social inequities and the real challenges to find healthy food in their neighborhood. A few weeks of these conversations and the students talked to the manager of the store close to the school to put fruit closer to register instead of chips and candy bars. They also became excited about the salad bar at school lunch after we went to talk to the school lunch staff who played up the salad bar.

Yet, we know, even with the most well-designed nutrition education, vegetable consumption is particularly hard to change, A meta-analysis found school-based nutrition education interventions increased vegetables by only 0.07 portions. ${ }^{1}$

\section{GOING FURTHER WITH THE NEW DGAS}

Despite 4 decades of Dietary Guidelines for Americans (DGAs), half of the adults in the United States have preventable, chronic diseases, many of which are related to diet and physical activity practices. ${ }^{2}$ We also know unhealthy diets increase the severity of COVID-19. ${ }^{3}$

The last 3 Dietary Guidelines Advisory Committee (DGAC) Reports discussed the importance of using a social ecological approach to address social determinants of health. ${ }^{4-6}$ We have started to do this by making meals offered through the National School Lunch and Breakfast Programs and meals offered through the Older American's Act meet the DGAs. ${ }^{2}$ Now it is time to take the next step. Let's make the materials and programming created to accompany the 9th edition of the DGAs truly take on-and eliminate-the inequities in the availability of health-promoting foods across different communities. Communities with Black, indigenous, and people of color have had inequitable access to health-promoting foods for generations. We have the opportunity to change this.

We can take advantage of the Center for Policy and Promotion's (CNPP) new infrastructure within the US Department of Agriculture (USDA) Food and Nutrition service. This provides increased opportunities for CNPP to work with federal nutrition assistance programs, especially SNAPEd, for innovative policies, system change, and environmental supports. Let's make this the time that we do upstream nutrition education so that in 5 years, when the next DGAC report is released, it can report on more equitable access to healthy foods, big improvements on Healthy Eating Index ${ }^{7}$ scores, and lower rates of diet-related, preventable chronic diseases.
Pamela Koch, EdD, RD

President, Society for Nutrition, Education and Behavior

\section{REFERENCES}

1. Evans CEL, Christian MS, Cleghorn CL, Greenwood DC, Cade JE. Systematic review and meta-analysis of school-based interventions to improve daily fruit and vegetable intake in children aged 5 to $12 \mathrm{y}$. Am J Clin Nutr. 2012;96:889-901.

2. US Department of Health and Human Services and US Department of Agriculture. 2015-2020 Dietary Guidelines for Americans. 8th ed. http://health.gov/dietaryguidelines/2015/guidelines/. Accessed September 21, 2020.

3. Butler MJ, Barrientos RM. The impact of nutrition on COVID-19 susceptibility and long-term consequences. Brain Behav Immun. 2020;87:53-54.

4. Dietary Guidelines Advisory Committee. Report of the Dietary Guidelines Advisory Committee on the Dietary Guidelines for Americans. Washington, DC: US Department of Agriculture, Agricultural Research Service; 2010.

5. Dietary Guidelines Advisory Committee. Scientific Report of the 2015 Dietary Guidelines Advisory Committee: Advisory Report to the Secretary of Health and Human Services and the Secretary of Agriculture. Washington, DC: US Department of Agriculture, Agricultural Research Service; 2015.

6. Dietary Guidelines Advisory Committee. Scientific Report of the 2020 Dietary Guidelines Advisory Committee: Advisory Report to the Secretary of Agriculture and the Secretary of Health and Human Services. Washington, DC: US Department of Agriculture, Agricultural Research Service; 2020.

7. Krebs-Smith S, Pannucci T, Subar A, Kirkpatrick S, Lerman J, Tooze J. Update of the Healthy Eating Index: HEI-2015. J Acad Nutr Diet. 2018;118: 1591-1602. 